\title{
The Impact of Characteristics of Regional Innovation Network Structure on Regional Innovation Output
}

\author{
Lei Zhao \\ Shanghai University \\ Shanghai, China
}

\begin{abstract}
This paper constructs the evaluation system of structural characteristics of regional innovation network, analyzes the influence mechanism of the regional characteristics of six dimensions of regional innovation network on regional innovation capability by regression analysis through the data of relevant statistical yearbooks. The results show that the network size, network structure, the openness of the network, and the strong and weak connection of the network have a significant positive effect on the regional innovation capability. However, the network concentration does not exert the required diffusion effect on growth pole and has no obvious effect on enhancing the innovation capability.
\end{abstract}

Keywords-regional innovation network; regional innovation output; structural holes

\section{INTRODUCTION}

The regional innovation network refers to the network relationship formed by the various actors (enterprises, universities, research institutes, intermediaries, financial institutions, governments) and individuals driven by interactive learning, aiming at system innovation in a certain region. Research shows that regional innovation networks not only root the economic activities of enterprises in local social networks, but also conduce to forming common values and industrial culture. They are conducive to cooperation, trust and commitment among enterprises and can prompt both parties to achieve and fulfill their agreement. They can also save the time and cost of searching for market information for companies and plays an important role in regional development. Therefore, studying the network mechanism of regional innovation has important practical significance for building a national or regional innovation system and enhancing the capability of independent innovation of China.

Grano vetter divides the structural features of regional innovation networks into network size, network concentration, structure holes and network openness while the performance of the main body relations includes strong connections and weak connections, and he emphasizes the importance of the impact of structural holes on regional innovation ability. In combination with the economic development in China, Lu Fang evaluates the structural characteristics of the network from five aspects: hierarchy, connection intensity, openness, proportion of regional innovation and structural hole, and then uses factorial evaluation to measure each structural features of the innovation network to propose the suggestion of improving the capacity of regional innovation. However, there are still some shortcomings in the research of regional innovation network and innovation output. For example, the research on regional innovation network is mainly based on case studies in specific regions, which makes the analysis of the results less universal. Based on this, this paper links the structure characteristics of regional innovation network in China with the regional innovation output by collecting and sorting out the statistical data, and empirically tests what kind of regional innovation network structure can effectively promote the improvement of regional innovation output to provide the corresponding enlightenment and policy reference for building regional innovation network in China.

\section{CONSTRUCTING THE INDEX SYSTEM OF STRUCTURE CHARACTERISTICS OF REGIONAL INNOVATIVE NETWORK}

\section{A. Construction Ideas on Index System of Structural Characteristics of Regional Innovation Network}

According to the existing literature, this paper subdivides the structural features of regional innovation network into six sub-dimensions, including network size, network concentration, structural hole and network openness, strong connection and weak connection.

Network size is the most basic feature of the regional network structure, which reflects the basic composition of the entire network. Usually, the size of regional innovation network refers to the number of nodes in the network. This article reflects it through the number of important nodes in the regional network and the corresponding ratio. Network concentration is different from the centrality (centrality) in the structure of enterprise network. It refers to the important strategic position of a participant in the network as a result of participating in a series of important junctures.

Structural hole is an important characteristic of network structure, which is proposed by Burt, referring to the nonredundant relationship between two connections. For the regional innovation network, the connections among the main innovators include direct connection and indirect connection. Structural holes are generated between two indirectly connected bodies. The existence of structural holes affects the movement of knowledge flow and exchange and sharing of information and becomes a breakpoint in the 
network. Meanwhile, it is also an opportunity for innovation, which serves as a bridge for the communication of the subject.

According to Granovette's viewpoint of Weak Power, maintaining a weak connection among businesses can deliver fresh knowledge and information and avoid the redundancy of knowledge and information. According to the strength of the network relationship, this paper divides the relationship dimension into strong connection and weak connection. Strong connection mainly refers to formal relations in regional innovation networks, including market transactions and cooperative networks. Formal relationships represent a continuous, focused and strongly interacting interrelation. Weak connection mainly refers to the informal relations in the network, which can be understood as non-written or unagreed default social relations, including public relations and personal relationships, as well as the role of bridge played by intermediary agencies in the innovation in regional innovation networks.

\section{B. Specific Indicators in the Index System of Structural Characteristics of Regional Innovation Network}

Based on the above measuring ideas and construction principles of regional innovation network structure, the structural features of the regional innovation network are divided into 17 program indicators, which are subordinate to six specific indicators according to the nature of their responses, as shown in "Table I".

TABLE I. The INDEX SYSTEM OF STRUCTURE CHARACTERISTICS OF REGIONAL NETWORK

\begin{tabular}{|c|c|c|}
\hline Objective & Index level & Scheme level \\
\hline \multirow{17}{*}{$\begin{array}{l}\text { Attributes of Regional } \\
\text { Network Structure }\end{array}$} & \multirow[t]{3}{*}{ Network size $\mathrm{C} 1$} & 1. The number of enterprises above the regional size (A1) \\
\hline & & 2. The number of regional research and development institutions (A2) \\
\hline & & 3. Number of colleges and universities (A3) \\
\hline & \multirow[t]{2}{*}{ Network concentration $\mathrm{C} 2$} & 4. Gross Regional Product (GCP: 100 million yuan) (A4) \\
\hline & & $\begin{array}{l}\text { 5. The proportion of Large and medium-sized enterprises in enterprises above } \\
\text { designated size (A5) }\end{array}$ \\
\hline & \multirow[t]{3}{*}{ Network openness C3 } & 6. Foreign import contracts by region (number of contracts) (A6) \\
\hline & & 7. Foreign introduction of contract by contract (contract value) (A7) \\
\hline & & 8. Trade dependence (A8) \\
\hline & \multirow[t]{3}{*}{ Structural hole $\mathrm{C} 4$} & 9. Number of Employment Agencies at the end of this year (A9) \\
\hline & & $\begin{array}{l}\text { 10. Fixed Assets Investment in Public Management and Social Organization } \\
\text { (100 million yuan) (A10) }\end{array}$ \\
\hline & & 11. Number of Public Libraries in Various regions (A11) \\
\hline & \multirow[t]{3}{*}{ Strong connection C5 } & 12. Turnover of Technology market (million) (A12) \\
\hline & & $\begin{array}{l}\text { 13. Funds of Science and Technology Activities in Colleges and Universities } \\
\text { of varoious Regions from Enterprises (10,000 yuan) (A13) }\end{array}$ \\
\hline & & $\begin{array}{l}\text { 14. funds of science and technology activities in Large and medium-sized } \\
\text { industrial enterprises from government (million) (A14) }\end{array}$ \\
\hline & \multirow[t]{3}{*}{ Weak connection $\mathrm{C} 6$} & 15. Number of Employment Training Center (A15) \\
\hline & & 16. total number of in-service staff in Vocational Training Center (A16) \\
\hline & & 17. Number of Successful Job recommendation (A17) \\
\hline
\end{tabular}

\section{DATA SOURCES AND RESEARCH METHODS}

\section{A. Data Sources}

The provinces and autonomous regions of our country are taken as the research objects and the authoritative statistical data are used, including China Statistical Yearbook, China Science and Technology Yearbook and China Statistical Yearbook in 2008 and the statistical yearbooks of all provinces, the data released by the website of National Statistics Bureau of China, and statistical bulletin published by government agencies.

\section{B. Dimensionless Treatment}

Efficacy coefficient method based on the principle of multi-objective programming, conducts dimensionless treatment to the data. First of all, we define the satisfaction value as the upper limit and the impermissible value as the lower limit in each index, measure the degree that each index is close to the satisfaction value and convert it into the corresponding evaluation score. In this paper, the maximum value of each indicator is set as a satisfactory value, and the minimum value is not permitted. The dimensionless formula is as follows:

$$
d_{i j}=\frac{X_{i j}-X_{j \min }}{X_{j \max }-X_{i j}} \times 100
$$

In the formula, $d_{i j}$ is the score of the jth index of the ith province or autonomous region. $X_{i j}$ is the actual value of the jth index of the ith province or autonomous region. $X_{j \min }$ is the minimum value of the $\mathrm{jth}$ index. $X_{j \max }$ is $\mathrm{j}$ the maximum value of the jth index. Serial number of Province and autonomous region $(i=1,2 \ldots 31) ; j$ is the serial number of evaluation index $(j=1,2, \ldots 17)$.

\section{Determination of the Weight of Evaluation Index}

With the help of statistical software SPSS19.0, factor analysis method is used to deal with the data. We can calculate the factor load matrix after rotation of each indicator, the corresponding eigenvalues of each factor and the cumulative contribution rate by using the maximum variance method. According to the principle that the eigenvalue is greater than 1 , four common factors are extracted instead of the original 17 indicators, and the 
cumulative variance contribution rate reaches $81 \%$, exceeding the general requirement of $80 \%$. The loss of the first four public factors is only $19 \%$, which can explain most of the data in the index system. Therefore, the factor analysis method is suitable for this paper, and this article selects four main factors. The factor loading matrix after rotation is shown in "Table II".

TABLE II. FACTORIAL LOADING MATRIX AFTER ROTATION

\begin{tabular}{|c|c|c|c|c|}
\hline \multicolumn{5}{|l|}{ Ingredient } \\
\hline & 1 & 2 & 3 & 4 \\
\hline $\begin{array}{l}\text { 1. The number of enterprises above the regional size } \\
\text { (A1) }\end{array}$ & 0.136 & 0.466 & -0.028 & 0.766 \\
\hline 2. Number of regional research and development & - & & & \\
\hline institutions (A2) & 0.029 & 0.186 & 0.878 & 0.765 \\
\hline 3. Number of colleges and universities (A3) & 0.117 & 0.108 & 0.259 & 0.752 \\
\hline 4. Gross Regional Product (GCP: 100 million yuan) & & & & \\
\hline (A4) & 0.559 & 0.171 & 0.134 & 0.634 \\
\hline 5. The proportion of Large and medium-sized & - & & & \\
\hline enterprises in enterprises above designated size (A5) & 0.176 & -0.103 & 0.018 & -0.929 \\
\hline 6. Foreign import contracts by region (number of & - & & & \\
\hline contracts) (A6) & 0.173 & 0.786 & 0.316 & 0.065 \\
\hline 7. Foreign introduction of contract by contract & - & & & \\
\hline (contract value) (A7) & 0.246 & 0.889 & 0.216 & -0.194 \\
\hline 8. Trade dependence (A8) & 0.237 & 0.852 & 0.132 & 0.147 \\
\hline $\begin{array}{l}\text { 9. Number of Employment Agencies at the end of } \\
\text { this year (A9) }\end{array}$ & 0.895 & -0.002 & -0.041 & 0.146 \\
\hline $\begin{array}{l}\text { 10. Fixed Assets Investment in Public Management } \\
\text { and Social Organization (100 million yuan) (A10) }\end{array}$ & 0.612 & 0.104 & 0.114 & 0.485 \\
\hline $\begin{array}{l}\text { 11. Number of Public Libraries in Various regions } \\
\text { (A11) }\end{array}$ & 0.872 & -0.054 & -0.104 & -0.058 \\
\hline 12. Turnover of Technology market (million) (A12) & 0.177 & 0.173 & 0.926 & -0.061 \\
\hline $\begin{array}{l}\text { 13. Funds of Science and Technology Activities in } \\
\text { Colleges and Universities in various Regions from }\end{array}$ & - & & & \\
\hline Enterprises (10,000 yuan) (A13) & 0.029 & 0.533 & 0.732 & 0.196 \\
\hline 14. funds of science and technology activities in & & & & \\
\hline $\begin{array}{l}\text { Large and medium-sized industrial enterprises from } \\
\text { government (million) (A14) }\end{array}$ & 0.315 & 0.689 & 0.421 & 0.181 \\
\hline 15. Number of Employment Training Center (A15) & 0.766 & 0.105 & 0 & 0.217 \\
\hline $\begin{array}{l}\text { 16. total number of in-service staff in Vocational } \\
\text { Training Center (A16) }\end{array}$ & 0.76 & 0.283 & 0.07 & -0.123 \\
\hline $\begin{array}{l}\text { 17. Number of Successful Job recommendation } \\
\text { (A17) }\end{array}$ & 0.738 & 0.031 & 0.091 & 0.287 \\
\hline
\end{tabular}

The first major factor has a large load in A4, A9, A10 and $\mathrm{A} 11$, and these indexes reflect the current development status of intermediary service agencies and management organizations and activities of related subject, which can be called the main factor representing structural holes; the second main factor has a large load in A6, A7 and A8. What the indexes reflect is mostly the degree of openness of the region, which is then called the main factor representing the degree of openness. The third main factor has large load in A7, A8 and A9. These indexes represent the connection between the various subjects in and out of the region and are therefore called the main factor of the connection. The load of the fourth main factor in A1, A2 and A3 is relatively large, and these indexes indicate the importance of the size of network subjects in the construction of regional innovation network, which is called the main factor of the innovation subject status.

\section{Multiple Regression Analysis}

Using the number of scientific and technological papers published in various regions as the output of innovation in each province and autonomous region, the author explores whether the regional innovation network structure can influence the regional innovation ability through regression analysis on the evaluation indicator of the regional innovation network in this paper.

\section{ANALYSIS AND ENLIGHTENMENT OF THE EMPIRICAL RESEARCH RESULTS}

\section{A. Score Results of Structural Characteristics of Innovation Network in Provinces and Autonomous Regions in China}

According to the above research method, the evaluation score of regional innovation network in China is shown in "Table III". 
TABLE III. EVALUATION SCORE OF STRUCTURAL Characteristics of REgIONAL INNOVATION NETWORK

\begin{tabular}{|c|c|c|c|c|c|c|}
\hline Region & Province & Dominant position & Connection intensity & Network openness & Structural hole & Overall score \\
\hline \multirow{12}{*}{$\begin{array}{l}\text { The east } \\
\text { region }\end{array}$} & Beijing & 47.2266 & 67.24977 & 100 & 55.14661 & 96.9784 \\
\hline & Tianjin & 59.0729 & 48.4327 & 51.88121 & 72.29755 & 63.3093 \\
\hline & Hebei & 56.1166 & 69.83393 & 47.29179 & 43.28974 & 63.3093 \\
\hline & Liaoning & 50.2104 & 69.61485 & 56.849 & 55.84879 & 74.5324 \\
\hline & Shanghai & 50.0155 & 66.91039 & 69.00519 & 100.0047 & 81.4388 \\
\hline & Jiangsu & 60.3149 & 91.16151 & 52.17372 & 87.01532 & 96.5468 \\
\hline & Zhejiang & 86.1415 & 47.14064 & 50.10349 & 55.95349 & 77.5539 \\
\hline & Fujian & 80.7282 & 66.74163 & 48.13441 & 47.73301 & 70.2158 \\
\hline & Shandong & 91.9661 & 89.45962 & 61.89932 & 46.52306 & 100 \\
\hline & Guangdong & 100 & 67.85289 & 57.46139 & 55.75438 & 95.2518 \\
\hline & Guangxi & 52.3786 & 53.06466 & 50.78435 & 40.79439 & 48.2014 \\
\hline & Hainan & 51.044 & 49.46238 & 48.74707 & 44.84892 & 43.8849 \\
\hline \multirow{10}{*}{$\begin{array}{l}\text { The central } \\
\text { region }\end{array}$} & Shanxi & 62.2704 & 51.52519 & 49.49735 & 41.18692 & 52.518 \\
\hline & Inner Mongolia & 60.4873 & 59.94237 & 50.66329 & 40.48121 & 56.8345 \\
\hline & Jilin & 44.8782 & 55.89289 & 47.69364 & 51.51941 & 52.0863 \\
\hline & Heilongjiang & 50.7492 & 65.72569 & 52.17372 & 49.16294 & 62.8777 \\
\hline & Anhui & 56.0203 & 58.87017 & 50.0797 & 46.62171 & 60.2878 \\
\hline & Jiangxi & 59.2434 & 74.74859 & 47.1813 & 49.27961 & 64.1727 \\
\hline & Henan & 47.2849 & 66.12049 & 49.55028 & 42.85754 & 56.4029 \\
\hline & Hubei & 40.6863 & 99.99986 & 52.58248 & 50.53453 & 73.2374 \\
\hline & Hunan & 52.4746 & 100 & 48.79433 & 44.17519 & 73.6691 \\
\hline & Chongqing & 54.9425 & 40 & 44.61824 & 61.91327 & 52.0863 \\
\hline \multirow{9}{*}{$\begin{array}{l}\text { The west } \\
\text { region }\end{array}$} & Sichuan & 40 & 68.86138 & 51.74403 & 55.21881 & 66.3309 \\
\hline & Guizhou & 69.0587 & 44.92426 & 48.98227 & 40.46909 & 50.7914 \\
\hline & Yunnan & 44.1726 & 61.42862 & 50.27674 & 40 & 52.0863 \\
\hline & Tibet & 46.25 & 46.23092 & 50.32505 & 43.23357 & 40 \\
\hline & Shaanxi & 48.9194 & 63.12759 & 59.72931 & 44.77239 & 65.8993 \\
\hline & Gansu & 52.9574 & 53.2752 & 51.70172 & 40.05866 & 50.3597 \\
\hline & Qinghai & 59.519 & 50.83154 & 45.01381 & 47.90459 & 49.4964 \\
\hline & Ningxia & 71.4199 & 44.95787 & 48.16477 & 45.03648 & 50.3597 \\
\hline & Xinjiang & 54.6678 & 55.3997 & 49.62193 & 40.75646 & 49.9281 \\
\hline
\end{tabular}

B. The Impact of Structural Characteristics of Regional Innovation Structure on Regional Innovation Output in China

In order to judge whether the structural characteristics of innovation networks in each dimension have an impact on the regional innovation output, this paper first divides the four degrees of innovation network structure characteristics into three groups of high, middle and low, uses single factor analysis to test whether there is significant difference between regional innovative output of high, middle and low groups and analyze the results shown in "Table IV".

TABLE IV. RESULTS OF ONE-WAY ANOVA

\begin{tabular}{|c|l|l|l|l|}
\hline Index & $\begin{array}{c}\text { Dominant } \\
\text { position }\end{array}$ & $\begin{array}{c}\text { Connection } \\
\text { intensity }\end{array}$ & $\begin{array}{c}\text { Network } \\
\text { openness }\end{array}$ & $\begin{array}{c}\text { Structural } \\
\text { hole }\end{array}$ \\
\hline \multirow{3}{*}{ Mean value } & 35.65 & 34.69 & 36.87 & 34.93 \\
\cline { 2 - 5 } & 25.87 & 24.57 & 25.56 & 27.66 \\
\cline { 2 - 5 } F value & 21.34 & 21.30 & 20.41 & 21.58 \\
\hline Sig & 11.67 & 14.77 & 12.86 & 827 \\
\hline
\end{tabular}

The results show that each innovation network has a strong connection with the regional innovation output, and then the author uses the method of unit regression to respectively carry out a simple regression on the regional innovation output with $\mathrm{C} 1, \mathrm{C} 2, \mathrm{C} 3$ and $\mathrm{C} 4$ and all have passed significance test. In order to further analyze the influence of structural characteristics of regional innovation network on regional innovation output, this paper uses
EVIEWS 5.0 software model to make multiple regression analysis. In order to avoid the problem of multicollinearity in the model, the author applies step-by-step regression and adds each variable in succession to make stepwise regression The variables failed the test are kicked off while those passed the test are retained. Finally, the multiple regression results of regional innovation network structure and regional innovation output is obtained:

$$
\mathrm{CR}=163781+0.133 \mathrm{C} 1+0.145 \mathrm{C} 2+0.128 \mathrm{C} 3
$$

This model reflects the main factors affecting regional innovation output in the regional innovation network structure. The coefficient of determination of the model is 0.9259 , with good imitative effect. Parameter estimation all passed the significance test, and there is no multicollinearity problem. According to the regression coefficient, if the other factors remain unchanged, the output of regional innovation will increase by 0.133 unit, 0.145 unit and 0.128 unit respectively when the score of dominant position, practice intensity and network openness of regional innovation network structure increase by 1 unit, which shows that the dominant position, connection intensity and network openness all play a significant role in promoting regional innovation output, and the promotion effect of the connection intensity is more obvious. 


\section{CONCLUSION}

A. To Vigorously Enhance the Connection Intensity between Subjects and Play the Role of Bridge of Intermediary in the Network Structure

Local governments should give full play to the regulatory role, actively build a platform for cooperation, exchange among various network entities and organize various forms of "promotion meetings", product expositions, trade fairs, etc., and enhance the frequency and density of connection among the subjects to form the atmosphere of close cooperation between the main subjects. At the same time, it should focus on supporting science and technology consulting service intermediaries for industries, industries and enterprises, financial intermediary service agencies for technology markets, talent markets, technology property rights transactions and venture capital investments, and technology-related service agencies of intellectual property rights, legislation and product quality supervision to create a good policy environment for the development of intermediaries.

\section{B. To Enhance Regional Openness to Achieve Regional and International Connection of Regional Innovation Networks}

The research data in this paper shows that the overall openness of the regional network in China is relatively low. Therefore, when building a regional innovation system, local governments should actively implement the strategy of science and technology opening up and interaction, carry out inter-regional cooperation in science and technology and construction of trans-regional innovation system, promote the integration of regional innovation subjects into a larger regional and global industrial value chain system, actively build economic and technological platforms for enterprises to achieve regional and international cooperation, actively introduce policies to encourage enterprises to embed interregional and international markets and promote the integration of regional innovation networks across provinces and regions through holding various cooperation and exchange activities, to realize the flow of innovative resources cross region and within the world.

\section{To Strengthen the Construction of Regional City Circle and Give Full Play to the Role of Radiation and Demonstration of Growth Pole}

The research in this paper shows that the influence of network concentration on regional innovation ability in China is not significant, and that is more obvious in the central and western regions. Therefore, the central and western regions should make full use of their own resource advantages and existing industrial advantages to actively promote the policy of combining "industrial growth pole" and "urban growth pole", seize the opportunity of China building the pilot area of policy of nationally-coordinated comprehensive reform in urban and rural areas in Chengdu and Chongqing, Wuhan city circle and Changsha, Zhuzhou and Xiangtan urban agglomerations, a pilot area of comprehensive reform for building a national resource- saving and environment-friendly society, establish and expand the "commuting circle" of central city group to surrounding cities, enhance the radiation and driving function of growth pole and greatly promote the frequent flow of resources such as information, technology, personnel and funds in the network, to giving full play to the synergistic effect and enhance the capability of innovation.

\section{REFERENCES}

[1] Kant I, Meredith J C. Critique of teleological judgement[M]. publisher not identified, 1928.

[2] Freeman C. Networks of innovators: a synthesis of research issues[J]. Research policy, 1991, 20(5): 499-514.

[3] Cooke P, Uranga M G, Etxebarria G. Regional innovation systems: Institutional and organisational dimensions[J]. Research policy, 1997, 26(4): 475-491.

[4] Morgan K, Cooke P. The associational economy: firms, regions, and innovation[J]. University of Illinois at Urbana-Champaign's Academy for Entrepreneurial Leadership Historical Research Reference in Entrepreneurship, 1999.

[5] Isaksen A. Building regional innovation systems: is endogenous industrial development possible in the global economy? [J]. Canadian journal of regional science, 2002, 24(1): 101-120.

[6] Kraatz M S. Learning by association Interorganizational networks and adaptation to environmental change $[\mathrm{J}]$. Academy of management journal, 1998, 41(6): 621-643.

[7] Cooke P, Schienstock G. Structural competitiveness and learning regions[J]. Enterprise and Innovation Management Studies, 2000, 1(3): 265-280.

[8] Nooteboom B. Learning and innovation in organizations and economies[M]. OUP Oxford, 2000.

[9] Storper M. The limits to globalization: technology districts and international trade[J]. Economic geography, 1992, 68(1): 60-93.

[10] Van Aken J E, Weggeman M P. Managing learning in informal innovation networks: overcoming the Daphne-dilemma[J]. R\&D Management, 2000, 30(2): 139-150.

[11] Castel-Branco C N. Economic Linkages between South Africa and Mozambique[J]. Unpublished Research Paper. London: Department of International Development, 2002.

[12] Hākansson H. Industrial Technological Development: ANetwork Approach[J]. 1987.

[13] Gai Wenqi, Wang Jici. On Regional Technology Innovation Model and Its Innovative Network - A Case Study of Zhongguancun in Beijing Journal of Peking University (Philosophy and Social Science, 1999,05:29-36.

[14] Caozi. Knowledge flows between regional innovation systems. China collective economy (the latter half of the month), 2008,03:48-49.

[15] Lu Fang, Cao Zi. An Empirical Study on the Characteristics of Regional Innovation Networks on the Innovation Ability of Enterprises. Statistics and Decision, 2010,21:187-188.

[16] Wei Shouhua, Wu Guisheng, Lv Xinlei. Influencing Factors of Regional Innovation Ability - Comment on the Regional Disparity of Innovation Ability in China. China Soft Science, 2010,09:76-85. 